\title{
Internal flow fraction as a potential indicator of pulmonary valve replacement in tetralogy of Fallot patients
}

\author{
Stephanie Clement-Guinaudeau ${ }^{1 *}$, Lee Neuman², Brandon K Fornwalt ${ }^{1}$, Jonathan Suever ${ }^{2}$, Marijn Brummer ${ }^{1}$, \\ Denver Sallee ${ }^{1}$, W James Parks', John N Oshinski ${ }^{1}$
}

From 2011 SCMR/Euro CMR Joint Scientific Sessions

Nice, France. 3-6 February 2011

\section{Objective}

Evaluate Internal Flow Fraction (IFF) in Tetralogy of Fallot (TOF) patients before Pulmonary Valve Replacement (PVR) to examine the progression of left ventricular dyssynchrony.

\section{Background}

Standard of care for TOF patients is a complete surgical repair in infancy but this results in free pulmonary regurgitation as no suitable long-term substitute for the obstructive valve is available. Although chronic pulmonary regurgitation can be well tolerated for decades, many patients $(>20 \%)$ eventually develop right ventricular dysfunction and often require PVR. Determining the optimal timing of PVR is difficult, and there is no clear consensus within the medical community.

In TOF patients before PVR, clinical studies have demonstrated a correlation between QRS duration and RV size with negative electromechanical interaction and dyssynchrony that progresses with RV enlargement. IFF is a quantitative measure of the energy loss throughout the cardiac cycle due to dyssynchronous contraction. We have developed a means of quantifying IFF noninvasively from cardiac magnetic resonance (CMR) images. In this study, we hypothesized that IFF within the left ventricle would increase in serial CMR exams prior to PVR.

\section{Methods}

We retrospectively analyzed two serial CMR studies in 24 pediatric patients with TOF and complete surgical repair before PVR. The average age at the first CMR was $10.8+/-5$ years and the average age at the second CMR was $14.1+/-5.4$ years. Images were obtained with 1.5T MRI systems; cine SSFP sequences were acquired in short axis with no gap and covered the entire left ventricle. Global left ventricular IFF was evaluated using an in-house developed MATLAB program.

\section{Results and discussion}

Global left ventricular IFF was significantly increased between the two CMR exams (mean IFF 0.33 vs 0.42 , $\mathrm{p}=0.017$ ), Figure 1 . The increase in left ventricular IFF

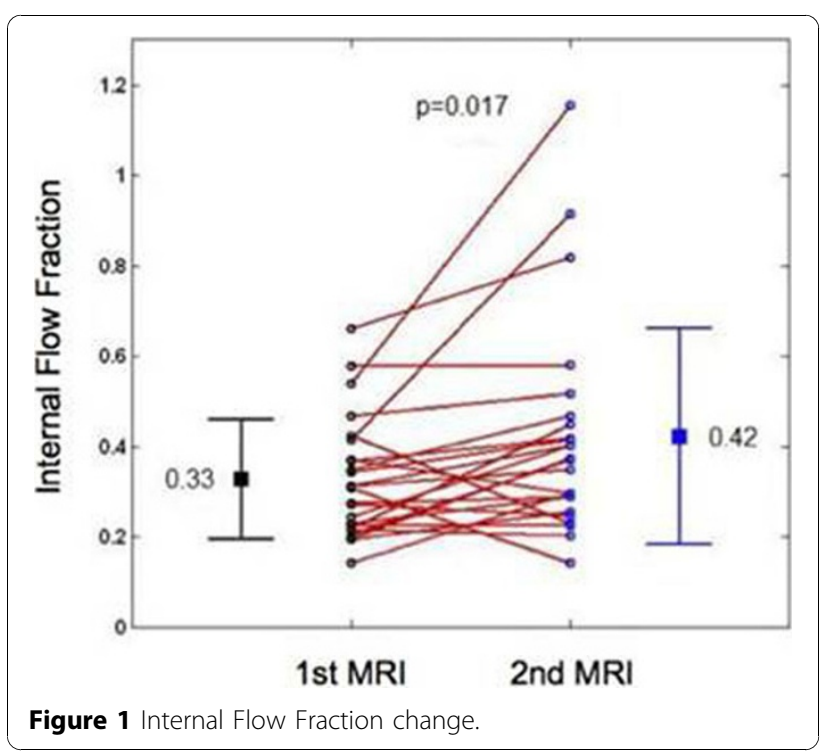

${ }^{1}$ Emory University School of Medicine, Atlanta, GA, USA

Full list of author information is available at the end of the article

(c) 2011 Clement-Guinaudeau et al; licensee BioMed Central Ltd. This is an open access article distributed under the terms of the B.1/ Central Creative Commons Attribution License (http://creativecommons.org/licenses/by/2.0), which permits unrestricted use, distribution, and reproduction in any medium, provided the original work is properly cited. 
indicates that left ventricular dyssynchrony increases over time in TOF patients with complete surgical repair. Further studies will examine the effect of PVR on IFF.

\section{Conclusion}

Left ventricular IFF increased over time in pediatric TOF patients with complete surgical repair. The increased IFF indicated more dyssynchronous contraction developed over time before PVR. The IFF could be a new marker for PVR timing in TOF patients and warrants further investigation.

\section{Author details}

${ }^{1}$ Emory University School of Medicine, Atlanta, GA, USA. ${ }^{2}$ Georgia Institute of Technology, Atlanta, GA, USA.

Published: 2 February 2011

Cite this article as: Clement-Guinaudeau et al: Internal flow fraction as a potential indicator of pulmonary valve replacement in tetralogy of Fallot patients. Journal of Cardiovascular Magnetic Resonance 2011 13(Suppl 1):P218.

Submit your next manuscript to BioMed Central and take full advantage of:

- Convenient online submission

- Thorough peer review

- No space constraints or color figure charges

- Immediate publication on acceptance

- Inclusion in PubMed, CAS, Scopus and Google Scholar

- Research which is freely available for redistribution

Submit your manuscript at www.biomedcentral.com/submit 